\title{
Expression of chemerin correlates with a poor prognosis in female breast cancer patients
}

This article was published in the following Dove Press journal:

Breast Cancer - Targets and Therapy

\author{
Ghada El-Sagheer' \\ Mariana Gayyed ${ }^{2}$ \\ Asmaa Ahmad' \\ Aliaa Abd El-Fattah ${ }^{3}$ \\ Manar Mohamed ${ }^{4}$ \\ 'Endocrinology Unit, Department \\ of Internal Medicine, Minia Faculty \\ of Medicine, Minia University, Minia, \\ Egypt; ${ }^{2}$ Department of Pathology, \\ Minia Faculty of Medicine, Minia \\ University, Minia, Egypt; ${ }^{3}$ Department \\ of Internal Medicine, Minia Faculty \\ of Medicine, Minia University, Minia, \\ Egypt; ${ }^{4}$ Department of Internal \\ Medicine, Deraya University, Minia, \\ Egypt
}

Correspondence: Ghada El-Sagheer Endocrinology Unit, Department of Internal Medicine, Minia University Hospital, M Badawy Street, 6I I I I El-Minia, Egypt

Tel +20 I095862058

Fax +20862342505

Email ghadagme70@yahoo.com
Objective: Chemerin was reported to regulate adipogenesis, metabolism, and immunity. But, its relation to cancer remains controversial. In breast cancer, chemerin expression has only been studied in serum, however, its expression in tissue, to our knowledge, has not been studied. The aim of this study was to investigate chemerin expression in breast cancer tissue in comparison to the adjacent normal tissue, and to assess its relationship to disease prognosis.

Methods: We examined chemerin expression in tissue with immunohistochemistry and analyzed the association of chemerin expression with the patients' clinical and pathological characteristics to determine its role as a predictor of the disease and its relation to disease prognosis.

Results: We detected a significantly higher expression of chemerin in the malignant vs the non-cancerous tissue specimens in 30/53, $(56 \%)$ patients, $(P=0.001)$. Moreover, its expression was significantly higher in the metastatic lymph nodes in comparison to the tumor tissues, $(P=0.01)$. Chemerin expression was significantly correlated with weight $(r=0.256, P=0.04)$, body mass index ( $r=0.233, P=0.03)$, tumor size $(r=0.235, P=0.03)$, lymph node metastasis $(r=0.265$, $P=0.045)$, distant metastasis ( $r=0.267, P=0.02)$, and tumor grading, $(r=0.421, P=0.004)$, while it was inversely significantly correlated with estrogen receptor and progesterone receptor expression in malignant breast tissues ( $P=0.038, r=-0.437$, and $P=0.047, r=-0.316)$, respectively. The area under the receiver operating characteristic curve for chemerin as a predictor of breast cancer was $0.82,(P<0.001$, sensitivity $89 \%$, and specificity $69 \%)$. The Kaplan-Meier survival curves revealed that patients with higher chemerin expression had worse overall survival in comparison to those with a lower chemerin expression, $(P=0.001)$.

Conclusion: Our results revealed higher chemerin expression in malignant vs adjacent normal breast tissue and lend support to a presumable role of chemerin tissue expression as an independent predictor of poor prognosis in breast cancer patients.

Keywords: chemerin expression, breast cancer, adipocyte development, obesity

\section{Introduction}

Breast cancer represents the most common female cancer in Egypt (32\%), ${ }^{1}$ affecting one in eight women, with nearly 700,000 deaths/year worldwide. ${ }^{2,3}$ Although the most important risk factor for breast cancer remains extended estrogen exposure by different etiologies, the exact pathophysiological mechanism has not been determined yet.

Obesity, a worldwide epidemic ${ }^{4}$ has been found to be associated with different kinds of malignancies. ${ }^{5}$ Post-menopausal obesity, an estrogen excess condition, has been reported to cause a $63 \%$ increase in breast cancer risk ${ }^{6}$ through many biologically active factors such as estrogen, insulin, IGF-I, leptin, and chemerin. ${ }^{7-10}$ The periadventitial fat stores have the capacity, in various manners, to produce bioactive peptides, 
adipokines. ${ }^{11,12}$ Through acting in an autocrine, paracrine, and endocrine manner, these adipokines have been shown to regulate several body functions and have been implicated in the pathophysiological mechanisms of clinical entities, including immunity, metabolism, and cancers. ${ }^{4,5,13}$

The adipokine, chemerin, is synthesized as a 163 -amino acid preproprotein (prochemerin), N-terminally cleaved with low activity. ${ }^{14}$ Following secretion, prochemerin can be C-terminally cleaved by a variety of extracellular proteases, resulting in several chemerin isoforms with varying lengths, receptor affinity, and biological activity. ${ }^{14}$ Its production from adipocytes is triggered by TNF-alpha. ${ }^{15}$ Being a chemoattractant protein, chemerin acts as a ligand for the G-protein-coupled receptors; CMKLR1 (or ChemR23), GPR1, and CCRL2. Only the chemerin/CMKLR1 axis' biological actions have been clearly described, ${ }^{16}$ and are mainly expressed in adipocytes, immune cells, and in breast tissue. ${ }^{17}$ It has been reported to be involved in various inflammatory diseases, as well as different malignancies. ${ }^{18}$ Chemerin has been identified to regulate adipogenesis and is associated with metabolic syndrome, polycystic ovary syndrome, and obesity. ${ }^{3,14,16,19}$

Chemerin's association with cancer is not clearly understood. ${ }^{3}$ The conflicting reports about the link between chemerin and cancer have caused this relation to be controversial, with reported tumorigenic and antitumor effects. While chemerin/CMKLR1 showed a tumorigenesis effect in squamous cell carcinoma of the oral tongue, glioblastoma, squamous esophageal cancer, gastric cancer ${ }^{20-23}$ and was shown to be extensively produced by neuroblastoma cells (tumor cell growth could be impaired by inhibition of the chemerin/CMKLR1 axis in vitro and in vivo) ${ }^{24}$ downregulation or an antitumorigenic effect has been suggested in hepatocellular carcinoma, non-small-cell lung cancer, and melanoma. ${ }^{25-27}$ The expression of chemerin in inflamed tissues, its pro- and anti-inflammatory properties, and its chemotactic recruitment of macrophages and other cells expressing CMKLR1 receptor, elucidate its role in inflammatory states. ${ }^{16,28}$ High chemerin levels may have an initiating role in carcinogenesis by promoting angiogenesis through inducing matrix metalloproteinase secretion and activity. ${ }^{29}$ Few studies have investigated chemerin expression in serum and tissue in gastric, colon, lung and esophageal cancers, and melanoma. In breast cancer, while chemerin expression has been extensively studied in serum, it has not been studied in malignant breast tissues. ${ }^{3}$ This study was designed to determine chemerin expression in the malignant tissue of women suffering from breast cancer in comparison to the adjacent normal tissue, and to assess its relationship with disease prognosis.

\section{Patients and methods}

\section{Tumor samples}

After approval from the Faculty of Medicine Research Ethics Committee, Minia University, 53 Egyptian patients suffering from breast cancer who attended the Minia University hospital and the Minia Oncology center were chosen and signed written informed consent for participation in the study. The patients were investigated and followed from January 2012 to December 2016. Patients with history of diabetes mellitus (DM), metabolic syndrome, and those suffering from coexisting illnesses such as chronic liver and kidney disease were excluded.

All the participants were evaluated according to a standardized form which included medical history (focusing on menstrual history, reproductive history, menopausal history, history of DM, and family history of breast cancer) and physical examination. Height in meters and weight in kilograms were measured, and the body mass index (BMI) was calculated [weight $(\mathrm{kg}) /$ height $(\mathrm{m})^{2}$ ]. Paraffin blocks of the malignant tissues, the adjacent non-malignant tissues, and the lymph node (LN) metastasis were obtained from each case. The clinical and pathological data are given in Table 1.

We performed immunohistochemical staining on $4 \mu \mathrm{m}$ thick sections of the most representative paraffin blocks from each tumor. Slides were heated at $60^{\circ} \mathrm{C}$ and de-paraffinized in xylene. Subsequently, they were rehydrated by replacing graded alcohol with water. Heat-induced antigen retrieval was achieved by boiling sections in a citrate buffer, $\mathrm{pH} 6$, in a microwave oven at $700 \mathrm{~W}$ for 20 minutes (four times for 5 minutes each). After boiling, sections were left to cool at room temperature and rinsed thoroughly with PBS for 5 minutes. Endogenous peroxidase was blocked with peroxidase block solution (provided in the EnVision kit, Dako Denmark A/S, Glostrup, Denmark) for 10 minutes and slides were rinsed with PBS. Sections were incubated for 30 minutes with primary mouse monoclonal anti-human chemerin antibody (Abcam, Cambridge, UK) using a 1:400 dilution. The same sections were processed without primary antibodies as negative control.

\section{Tissue classification}

Diagnoses were made based on paraffin-embedded $4 \mu \mathrm{m}$ tissue sections after $\mathrm{H} \& \mathrm{E}$ staining. Tissues were classified according to histological subtypes as invasive ductal car- 
Table I Demographic, clinical, and pathological characteristics of the female breast cancer patients

\begin{tabular}{|c|c|}
\hline Variable & Patients $(n=53)$ \\
\hline Mean age (years) & $51.79 \pm 11.975(24-79)$ \\
\hline Weight (kg) & $74.28 \pm I I .45(52-105)$ \\
\hline Height $(\mathrm{cm})$ & $156.28 \pm 5.07$ \\
\hline $\mathrm{BMI}\left(\mathrm{kg} / \mathrm{m}^{2}\right)$ & $30.48 \pm 4.9157(20.4-44.9)$ \\
\hline Mean fasting glucose $(\mathrm{mg} / \mathrm{dL})$ & $5.04 \pm 0.75(3.33-6.67)$ \\
\hline Hemoglobin (gm/dL) & $13.6+1.3(10.0-17.0)$ \\
\hline Total leukocytes count $\left(\mathrm{I}, 000\right.$ cells $\left./ \mathrm{mm}^{3}\right)$ & $6.502 \pm 1.8629(4.1-10.3)$ \\
\hline Neutrophils $\left(I, 000\right.$ cells $\left./ \mathrm{mm}^{3}\right)$ & $4.074 \pm I .49(I .6-7.1)$ \\
\hline Lymphocytes $\left(I, 000\right.$ cells $\left./ \mathrm{mm}^{3}\right)$ & $2.136 \pm 0.6397(0.6-3.7)$ \\
\hline Platelets (I,000 platelets $\left./ \mathrm{mm}^{3}\right)$ & $302.43 \pm 95.74(104-569)$ \\
\hline $\begin{array}{l}\text { Pathological diagnosis } \\
\text { Invasive ductal carcinoma }\end{array}$ & $53(100 \%)$ \\
\hline Tumor surface area $\left(\mathrm{cm}^{2}\right)$ & $10.591 \pm 7.3685(1.0-30.0)$ \\
\hline $\begin{array}{l}\text { Lymph node (LN) metastases } \\
\text { Negative } \\
\text { Positive } \\
\text { Number of LN metastasis }\end{array}$ & $\begin{array}{l}7(14 \%) \\
46(86 \%) \\
14.47 \pm 7.3685(0-30) \\
\end{array}$ \\
\hline $\begin{array}{l}\text { Distant metastasis (\%) } \\
\text { Negative/positive }\end{array}$ & $24 / 29(45 / 55 \%)$ \\
\hline $\begin{array}{l}\text { Tumor grading } \\
\text { Grade I } \\
\text { Grade II } \\
\text { Grade III }\end{array}$ & $\begin{array}{l}0(0 \%) \\
43(81.1 \%) \\
10(18.9 \%)\end{array}$ \\
\hline
\end{tabular}

Note: Data shown as mean \pm SD (range) or $n(\%)$.

Abbreviation: $\mathrm{BMI}$, body mass index.

cinoma of different grades $(\mathrm{n}=53)$. Invasive tumors were evaluated according to the Scarff-Bloom-Richardson grade classification modified by Elston et al..$^{30}$ Normal tissue adjacent to breast cancer was also analyzed as control $(n=53)$. The staging of breast cancer was determined based on the TNM system based on definitions and recommendations of European Society of Medical Oncology, 2015. ${ }^{31}$

\section{Interpretation of immunohistochemistry staining}

Positive signal for chemerin was located mainly in the cytoplasm and to a lesser extent the nucleus of the ductal cells and the score was semi-quantitatively estimated on the basis of both percentage and intensity of positively stained tumor cells. Five views were examined per slide, and 100 cells were counted per view at $\times 400$ magnification. The intensity of chemerin staining was classified using the 4-point scale as 0 (no signal), 1 (weak staining), 2 (moderate staining), 3 (strong staining). Percentage scores were assigned as 0 , no staining; $1,1 \%-25 \% ; 2,26 \%-50 \%$; 3, 51\% $75 \%$; and 4, 76\%-100\%. Their multiplication (intensity score $\times$ area score) was calculated in each area. Thus, the score should range from 0 to
12. For statistical analysis, chemerin immunostaining scores of 0-4 were defined as weak or low expression, and scores of 5-12 were defined as high expression.

\section{Statistical analysis}

The statistical analyses were performed using SPSS version 24.0 (IBM Corporation, Armonk, NY, USA). Data on normal distribution were expressed as mean \pm SD and were compared using independent samples $t$-test. Categorical variables were expressed as percentage and were compared using the chi-squared test or Fisher's exact test, as appropriate. Nonparametric variables were analyzed using the Mann-Whitney $U$ test. The Pearson correlation coefficients were used to study the correlation between different parametric variables. Spearman rank correlation was used to quantify the association between continuous or ordered categorical variables. Receiver operating characteristic (ROC) curve analysis and the area under the curve (AUC) were calculated. Kaplan-Meier survival curves were calculated for disease-free survival. A multivariate analysis was performed using the Cox regression model to study the effects of different variables on survival $P$-value $<0.05$ was considered as statistically significant.

\section{Results}

Table 1 shows a summary of the clinical and pathological characteristics of the cases included in this study. A total of 53 patients with primary breast cancer were included. The mean patients' age was $51.79 \pm 11.975$ years at a range of (24-79), their mean BMI was 30.48 \pm 4.9157 (20.4-44.9). Their pathological diagnosis was invasive ductal carcinoma in 53 cases $(100 \%)$. The mean tumor surface area was $10.591 \pm 7.3685 \mathrm{~cm}^{2}$ at a range of $1.0-30$. LN metastasis was present in $86 \%$ of cases, the mean number of $\mathrm{LN}$ metastasis was $14.47 \pm 7.3685$ at a range of $0-30$. Distant metastasis was present in $45 \%$ of cases. Tumor grading was moderate in 43 cases $(81.1 \%)$, and high in ten cases $(18.9 \%)$.

\section{The expression of chemerin in breast carcinomas versus normal breast tissue}

Immunohistochemistry was performed in 53 breast cancer specimens and their corresponding normal tissues. Of the 53 patients, 30 cases (56\%) showed a high expression level of chemerin in malignant tissue vs non-cancerous tissue specimens $(P=0.001)$. The chemerin protein appeared to be expressed mainly in the cytoplasm and to a lesser extent in the nuclei of tumor cells, Table 2 and Figure 1, also, the chemerin expression in the metastatic LNs was significantly higher than the malignant breast tissue (Figures 2 and 3, $(P=0.01)$. 
Table 2 The chemerin expression and distribution in malignant vs benign breast tissue

\begin{tabular}{|l|l|l|l|}
\hline Variable & $\begin{array}{l}\text { Normal } \\
\mathbf{( 5 3 )}\end{array}$ & $\begin{array}{l}\text { Malignant } \\
\text { tissue } \\
(\mathbf{n}=53)\end{array}$ & P-value \\
\hline $\begin{array}{l}\text { Chemerin } \\
\text { expression \% }\end{array}$ & & & \\
Low expression & $71.4 \%$ & $44 \%$ & 0.001 \\
Overexpression & $28.6 \%$ & $56 \%$ & \\
\hline
\end{tabular}

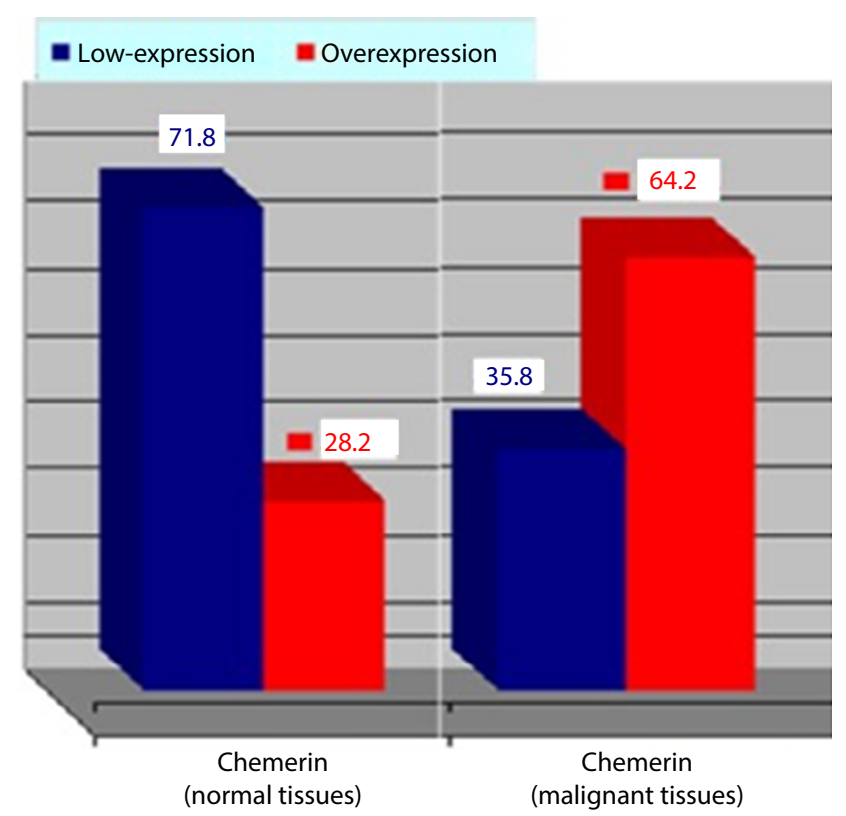

Figure I Chemerin expression in malignant vs normal breast tissues.

\section{Correlations of chemerin expression with clinicopathologic variables}

Chemerin expression was positively correlated with patients' weight, BMI, tumor size, $\mathrm{LN}$ metastasis, distant metastasis, and tumor grading $(r=0.256, P=0.04 ; r=0.233, P=0.03$; $r=0.235, P=0.03 ; r=0.265, P=0.045 ; r=0.267, P=0.02$; $r=0.421, P=0.004)$, respectively, and was inversely correlated with estrogen receptor $(E R)$ and progesterone receptor $(\mathrm{PR})$ expression in malignant breast tissues $(r=-0.437, P=0.038)$, and ( $r=-0.316, P=0.047$ ), respectively. Correlations of chemerin expression with clinicopathological variables were shown in Table 3.

\section{Chemerin expression as predictor and prognostic factor of breast cancer}

Chemerin expression was evaluated as a predictor of breast cancer, Figure 4. The AUC was $0.82(P<0.001)$, with a sensitivity of $89 \%$ and specificity of $69 \%$. The 5 -year disease-free

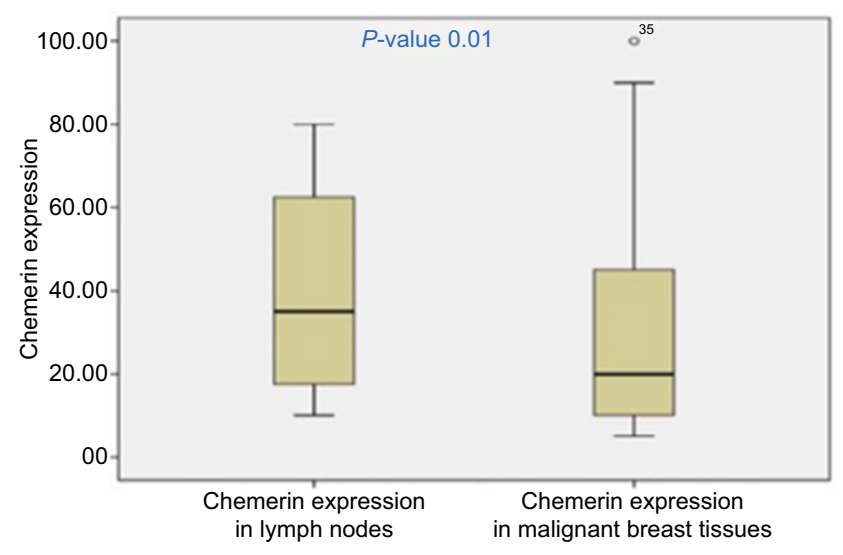

Figure 2 Chemerin expression in the metastatic lymph nodes vs malignant breast tissues.

Table 3 Associations of chemerin expression with clinical and pathological characteristics in women with breast cancer

\begin{tabular}{|l|l|l|}
\hline Variable & \multicolumn{2}{|l|}{ Chemerin expression } \\
\hline & $\boldsymbol{r}$ & $\boldsymbol{P}$ \\
\hline Age (years) & -0.059 & 0.673 \\
\hline Weight $(\mathrm{kg})$ & 0.256 & 0.04 \\
\hline Height $(\mathrm{m})$ & -0.014 & 0.921 \\
\hline BMI $\left(\mathrm{kg} / \mathrm{m}^{2}\right)$ & 0.233 & 0.03 \\
\hline FBS $(\mathrm{mmol} / \mathrm{L})$ & 0.106 & 0.450 \\
\hline Tumor size $(\mathrm{cm})$ & 0.235 & 0.031 \\
\hline LN metastasis & 0.265 & 0.045 \\
\hline Distant metastasis & 0.267 & 0.02 \\
\hline Tumor grading & 0.421 & 0.004 \\
\hline ER expression & -0.437 & 0.038 \\
\hline PR expression & -0.316 & 0.047 \\
\hline
\end{tabular}

Abbreviations: BMI, body mass index; ER, estrogen receptor; FBS, fasting blood sugar; LN, lymph node; PR, progesterone receptor.

survival rates among patients with higher expression were significantly worse than patients with low chemerin expres$\operatorname{sion}(P=0.001)$, Figure 4. Figure 5 showed the Kaplan-Meier survival curves for the patients according to chemerin expression level. A significant difference in survival was observed between patients with high chemerin expression levels $(\mathrm{n}=30)$ in comparison to those with low chemerin expression levels $(n=23)$. To assess other factors affecting 5-year disease-free survival, we used the Cox proportional hazard analysis. The factors considered were age, BMI, fasting blood sugar, tumor size, differentiation grade, histological type, and chemerin expression. The univariate Cox regression analysis indicated that TNM stage (HR 6.23, 95\% CI 2.86-13.56; $P=0.001$ ), differentiation grade (HR 21.28, 95\% CI 7.81-58; $P=0.001$ ), and chemerin expression level (HR 2.07, 95\% CI 1.08-3.97; 


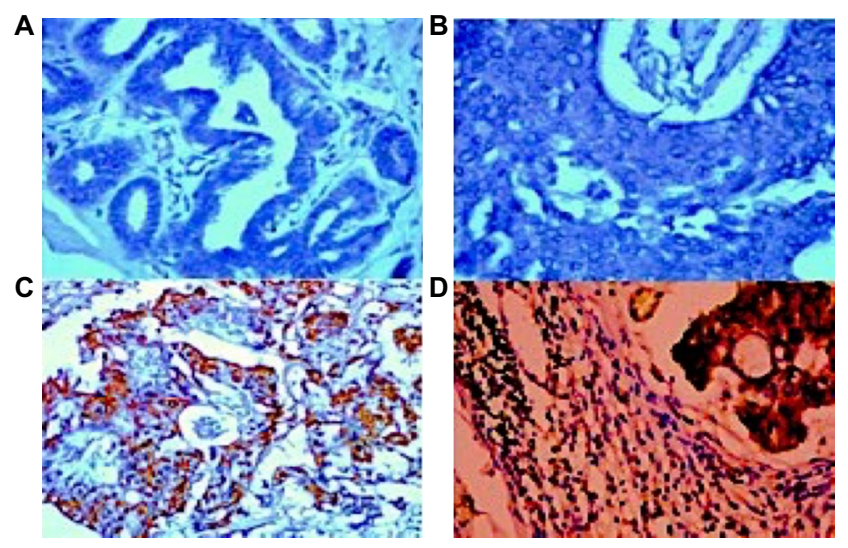

Figure 3 Representative microphotographs of immunohistochemical analysis of chemerin antigen expression in human normal breast tissue and breast cancer tissue. Notes: (A) No detectable chemerin antigen expression was observed in ductal cells of normal breast tissue. (B) Weak chemerin immune-reactivity was observed in the tumor cells of breast cancer tissue. (C) Intense and widespread chemerin immunereactivity was observed in the cytoplasm of tumor cells. (D) Intense chemerin immune-reactivity was observed in the tumor cells infiltrating the regional lymph node. Original magnification, $\times 400$.

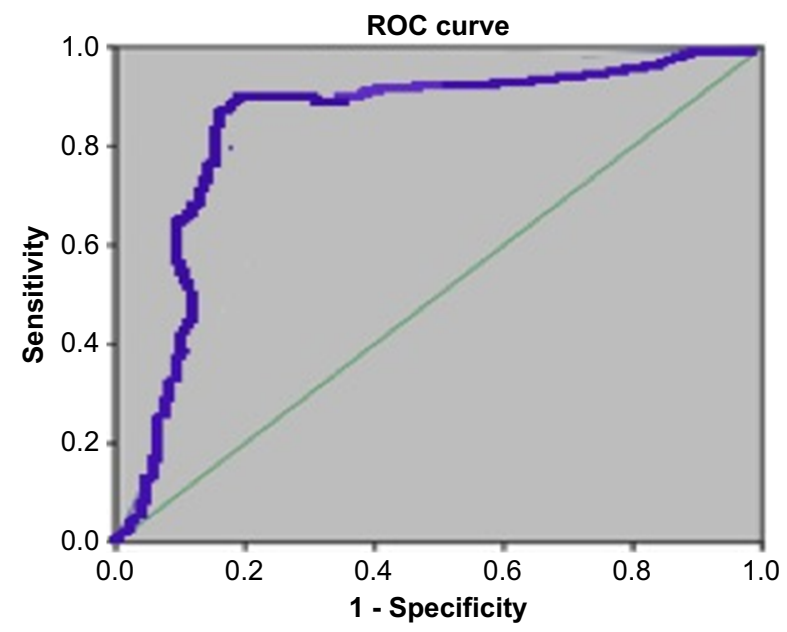

Figure 4 Receiver operating characteristic (ROC) curves of chemerin expression differentiating malignant from adjacent non-tumor breast tissue. Note: Area under the curve of chemerin overexpression $=82 \%$.

$P=0.029)$ were independent factors affecting the 5-year disease-free survival rate.

\section{Discussion}

To the best of our knowledge, this is the first study which has addressed chemerin expression in breast cancer tissue. In this study, we found that chemerin expression was significantly higher in the cancer tissue in comparison to adjacent normal breast tissue. Moreover, chemerin expression was higher in the metastatic LNs in comparison to the tumor tissues. Its

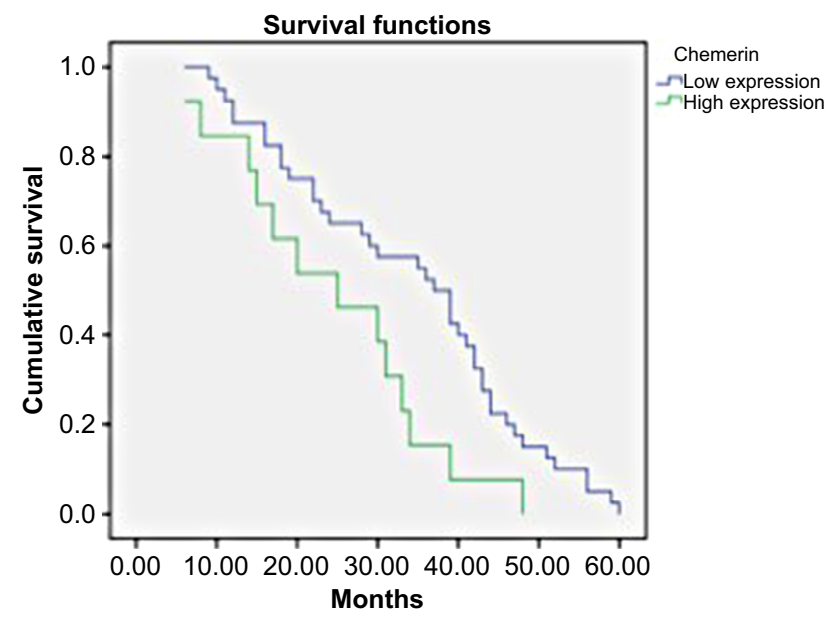

Figure 5 Kaplan-Meier survival curves of female patients with breast cancer according to chemerin expression levels.

Notes: The Kaplan-Meier survival curves of 53 females with breast cancer according to chemerin expression levels. A significant difference in survival was observed between patients with high chemerin expression levels $(n=30)$ and those with low chemerin expression levels $(n=23)$. The prognosis of patients with a high expression of chemerin was worse than that of patients with low expression $(P=0.00 \mathrm{I})$.

expression was strongly related to the tumor size, presence of LN or distant metastasis, and tumor grading. Similar to existing literature, chemerin levels were found to be strongly, positively correlated with weight and BMI. While chemerin levels was inversely correlated with ER and PR expression in the malignant breast tissue. Based on the ROC curve analysis, the AUC of chemerin was 0.82 , with a sensitivity of $89 \%$ and specificity of $69 \%$. The Kaplan-Meier survival curves revealed that patients with high expression of chemerin had unfavorable disease-free survival in comparison to those with low expression.

Several adipokines such as leptin, resistin, apelin, and visfatin have been implicated in cancer development through different pathophysiological mechanisms such as inflammation, insulin resistance, and sex hormones' production. Their increased levels were reported to play a pro-carcinogenic role. ${ }^{4}$ On the contrary, other adipokines such as adiponectin were reported to have an anti-carcinogenic role. ${ }^{3}$ The recently discovered adipokine, chemerin (also known as TIG-2 or RARRES2), is a chemoattractant factor that was found to regulate adipocyte development, metabolic functions, and immunity ${ }^{32,33}$ and has been associated with obesity, metabolic syndrome, insulin resistance, inflammatory diseases, and cancer. ${ }^{18,20-22,25,34-38}$ Many reports have attempted to elucidate the pathophysiological mechanisms through which chemerin could induce its effects. Chemerin promotes tumorigenesis by triggering the production and activity of matrix metalloproteinase, which plays a crucial role in angiogenesis, while the antitumor role for high chemerin levels has been reported 
to be through recruitment of natural killer (NK) cells which would help the immune system to recognize and fight the cancer cells..$^{20-23,39}$ Also, chemerin could induce the initiation of the innate immune response and inflammatory processes by attracting the antigen presenting cells. ${ }^{17,25,40}$ Therefore, with high chemerin levels, the immune system recognizes cancer cells and fights them. The inflammatory pathogenic nature of breast cancer may represent another mechanism that may link chemerin expression with breast cancer. ${ }^{41,42}$ Breast cancer stem cells' biology has been reported to be affected by certain immune mediators. ${ }^{43,44}$ Chemerin has also been reported to be associated with numerous pro-inflammatory cytokines related to cytotoxic cell-mediated immunity such as IL-6, IL-8, and TNF-alpha, ${ }^{45,46}$ which represent inflammatory mediators in the breast. ${ }^{47,48}$

When compared to the adjacent Barrett's tissue, the malignant tissues of esophageal adenocarcinoma were reported to have high chemerin expression, ${ }^{49,50}$ which confirmed an association between overexpression of chemerin and chemR23 and a more invasive esophageal squamous cell carcinoma. Recently, $\mathrm{Xu}$ et $\mathrm{al}^{51}$ reported that chemerin expression in serum may be considered as a serum biomarker for diagnosis and prognosis in non-small-cell lung cancer patients.

Obesity, a metabolic disorder, is a well-established risk factor for the development of cancer, including breast cancer. Chemerin levels were reported to be significantly associated with obesity; ${ }^{19}$ its plasma levels are significantly heritable and may be a stimulator of angiogenesis. ${ }^{52}$ The effects of adiposederived angiogenic factors in promotion of tumor growth have been demonstrated in experimental studies. ${ }^{53,54}$ Elevated chemerin levels secondary to obesity may further contribute to chemerin's angiogenic properties through triggering the production and activity of the matrix metalloproteinase, formation of new capillary-like structures, and vascularization of endothelial cells. ${ }^{52}$ In agreement with Catalan et al, ${ }^{55}$ our study revealed that increased serum chemerin levels were correlated with BMI and obesity.

Although many studies have demonstrated the relationship between chemerin expression in serum and tissue and many types of tumors, ${ }^{6-11}$ for breast cancer, chemerin expression has only been studied in serum. ${ }^{3}$ It has been reported that serum chemerin levels were not associated with tumor stage in breast cancer. ${ }^{3}$ In the current study, chemerin expression in tissue was associated with unfavorable clinical and pathological variables, TNM staging, and LN and distant metastasis. Chemerin levels were higher in the metastatic LNs in comparison to malignant breast tissue, while they were negatively correlated with ER and PR expression. This was also proved by Kaplan-Meier survival curves and the ROC curve. Although further investigations are required, the results of this study may imply that increased chemerin levels might serve as a marker for diagnosis, progression, and prognosis of breast cancer patients.

This study has some limitations including, small sample size, all patients had grade II and III cancer, while no patient had grade I or IV, and lack of some investigations at our center such as Western blot analysis and verification of some upstream and downstream genes of chemerin in the tumor sections and the adjacent normal tissues. Therefore, our findings need further evaluation in prospective studies with larger sample sizes to determine a causal relationship of high chemerin expression. The expression of inflammatory and immunological markers, as the natural killer cells, in the malignant and adjacent benign tissue also, need to be clarified in further studies.

\section{Conclusion}

The higher chemerin expression in malignant in comparison to normal breast tissues and the increased expression in the LN metastatic tissue may introduce chemerin as an independent predictor of poor prognosis of women with breast cancer.

\section{Disclosure}

The authors report no conflicts of interest in this work.

\section{References}

1. Ibrahim AS, Khaled HM, Mikhail NN, Baraka H, Kamel H. Cancer incidence in egypt: results of the national population-based cancer registry program. J Cancer Epidemiol. 2014;2014:1-18.

2. Ferlay J, Steliarova-Foucher E, Lortet-Tieulent J, et al. Cancer incidence and mortality patterns in Europe: estimates for 40 countries in 2012. Eur J Cancer. 2013;49(6):1374-1403.

3. Akin S. Serum Chemerin Level in Breast Cancer. Int J Hematol Oncol. 2017;27(2):127-132.

4. Cabia B, Andrade S, Carreira MC, Casanueva FF, Crujeiras AB. A role for novel adipose tissue-secreted factors in obesity-related carcinogenesis. Obes Rev. 2016;17(4):361-376.

5. Booth A, Magnuson A, Fouts J, Foster M. Adipose tissue, obesity and adipokines: role in cancer promotion. Horm Mol Biol Clin Investig. 2015;21(1):57-74.

6. Calle EE, Rodriguez C, Walker-Thurmond K, Thun MJ. Overweight, obesity, and mortality from cancer in a prospectively studied cohort of U.S. adults. $N$ Engl J Med. 2003;348(17):1625-1638.

7. Calle EE, Thun MJ. Obesity and cancer. Oncogene. 2004;23(38): 6365-6378.

8. Guastamacchia E, Resta F, Triggiani V, et al. Evidence for a putative relationship between type 2 diabetes and neoplasia with particular reference to breast cancer: role of hormones, growth factors and specific receptors. Curr Drug Targets Immune Endocr Metabol Disord. 2004;4(1):59-66. 
9. Garofalo C, Surmacz E. Leptin and cancer. J Cell Physiol. 2006;207(1): $12-22$.

10. Gunter MJ, Hoover DR, Yu H, et al. Insulin, insulin-like growth factor-I, and risk of breast cancer in postmenopausal women. J Natl Cancer Inst. 2009;101(1):48-60.

11. Ronti T, Lupattelli G, Mannarino E. The endocrine function of adipose tissue: an update. Clin Endocrinol. 2006;64(4):355-365.

12. Gustafson B. Adipose tissue, inflammation and atherosclerosis. J Atheroscler Thromb. 2010;17(4):332-341.

13. Kostopoulos CG, Spiroglou SG, Varakis JN, Apostolakis E, Papadaki HH. Chemerin and CMKLR1 expression in human arteries and periadventitial fat: a possible role for local chemerin in atherosclerosis? BMC Cardiovasc Disord. 2014;14:56.

14. Mattern A, Zellmann T, Beck-Sickinger AG, Processing B-SAG. Processing, signaling, and physiological function of chemerin. IUBMB Life. 2014;66(1):19-26.

15. Parlee SD, Ernst MC, Muruganandan S, Sinal CJ, Goralski KB. Serum chemerin levels vary with time of day and are modified by obesity and tumor necrosis factor- $\{$ alpha\}. Endocrinology. 2010;151(6):2590-2602.

16. Bondue B, Wittamer V, Parmentier M. Chemerin and its receptors in leukocyte trafficking, inflammation and metabolism. Cytokine Growth Factor Rev. 2011;22(5-6):331-338.

17. Wittamer V, Franssen JD, Vulcano M, et al. Specific recruitment of antigen-presenting cells by chemerin, a novel processed ligand from human inflammatory fluids. J Exp Med. 2003;198(7):977-985.

18. Goralski KB, Mccarthy TC, Hanniman EA, et al. Chemerin, a novel adipokine that regulates adipogenesis and adipocyte metabolism. $J$ Biol Chem. 2007;282(38):28175-28188.

19. Bozaoglu K, Bolton K, Mcmillan J, et al. Chemerin is a novel adipokine associated with obesity and metabolic syndrome. Endocrinology. 2007; 148(10):4687-4694.

20. Wang N, Wang QJ, Feng YY, Shang W, Cai M. Overexpression of chemerin was associated with tumor angiogenesis and poor clinical outcome in squamous cell carcinoma of the oral tongue. Clin Oral Investig. 2014;18(3):997-1004.

21. Kumar JD, Holmberg C, Kandola S, et al. Increased expression of chemerin in squamous esophageal cancer myofibroblasts and role in recruitment of mesenchymal stromal cells. PLoS One. 2014;9(7): e104877.

22. Wang $\mathrm{C}, \mathrm{Wu} \mathrm{WK}$, Liu $\mathrm{X}$, et al. Increased serum chemerin level promotes cellular invasiveness in gastric cancer: a clinical and experimental study. Peptides. 2014;51:131-138.

23. Yamaguchi Y, Du XY, Zhao L, Morser J, Leung LL. Proteolytic cleavage of chemerin protein is necessary for activation to the active form, Chem157S, which functions as a signaling molecule in glioblastoma. J Biol Chem. 2011;286(45):39510-39519.

24. Tümmler C, Snapkov I, Wickström M, et al. Inhibition of chemerin/ CMKLR1 axis in neuroblastoma cells reduces clonogenicity and cell viability in vitro and impairs tumor growth in vivo. Oncotarget. 2017;8(56):95135-95151.

25. Pachynski RK, Zabel BA, Kohrt HE, et al. The chemoattractant chemerin suppresses melanoma by recruiting natural killer cell antitumor defenses. $J$ Exp Med. 2012;209(8):1427-1435.

26. Imai $\mathrm{K}$, Takai K, Hanai T, et al. Impact of serum chemerin levels on liver functional reserves and platelet counts in patients with hepatocellular carcinoma. Int J Mol Sci. 2014;15(7):11294-11306.

27. Zhao S, Li C, Ye Y-Bin, Peng F, Chen Q. Expression of chemerin correlates with a favorable prognosis in patients with non-small cell lung cancer. Lab Med. 2011;42(9):553-557.

28. Roh SG, Song SH, Choi KC, et al. Chemerin--a new adipokine that modulates adipogenesis via its own receptor. Biochem Biophys Res Commun. 2007;362(4):1013-1018.

29. Kaur J, Adya R, Tan BK, Chen J, Randeva HS. Identification of chemerin receptor (ChemR23) in human endothelial cells: chemerininduced endothelial angiogenesis. Biochem Biophys Res Commun. 2010;391(4):1762-1768.
30. Elston CW, Ellis IO. Pathological prognostic factors in breast cancer. I. The value of histological grade in breast cancer: experience from a large study with long-term follow-up. Histopathology. 1991;19(5):403-410.

31. Senkus E, Kyriakides S, Ohno S, et al. Primary breast cancer: ESMO Guidelines for diagnosis, treatment and follow-up. Ann Oncol. 2015;26(5):v8-v30.

32. Ernst MC, Sinal CJ. Chemerin: at the crossroads of inflammation and obesity. Trends Endocrinol Metab. 2010;21(11):660-667.

33. Ernst MC, Issa M, Goralski KB, Sinal CJ. Chemerin exacerbates glucose intolerance in mouse models of obesity and diabetes. Endocrinology. 2010;151(5):1998-2007.

34. Landgraf K, Friebe D, Ullrich T, et al. Chemerin as a mediator between obesity and vascular inflammation in children. J Clin Endocrinol Metab. 2012;97(4):E556-E564

35. Kulig P, Kantyka T, Zabel BA, et al. Regulation of chemerin chemoattractant and antibacterial activity by human cysteine cathepsins. $J$ Immunol. 2011;187(3):1403-1410.

36. Schultz S, Saalbach A, Heiker JT, et al. Proteolytic activation of prochemerin by kallikrein 7 breaks an ionic linkage and results in C-terminal rearrangement. Biochem J. 2013;452(2):271-280.

37. Berg V, Sveinbjornsson B, Bendiksen S, Brox J, Meknas K, Figenschau Y. Human articular chondrocytes express ChemR23 and chemerin; ChemR23 promotes inflammatory signalling upon binding the ligand chemerin (21-157). Arthritis Res Ther. 2010;12(6):R228.

38. Rourke JL, Dranse HJ, Sinal CJ. Towards an integrative approach to understanding the role of chemerin in human health and disease. Obes Rev. 2013;14(3):245-262.

39. Parolini S, Santoro A, Marcenaro E, et al. The role of chemerin in the colocalization of $\mathrm{NK}$ and dendritic cell subsets into inflamed tissues. Blood. 2007;109(9):3625-3632.

40. Wittamer V, Bondue B, Guillabert A, Vassart G, Parmentier M, Communi D. Neutrophil-mediated maturation of chemerin: a link between innate and adaptive immunity. J Immunol. 2005;175(1):487-493.

41. Balkwill F, Mantovani A. Inflammation and cancer: back to Virchow? Lancet. 2001;357(9255):539-545.

42. Arias JI, Aller MA, Arias J. Cancer cell: using inflammation to invade the host. Mol Cancer. 2007;6:29.

43. Boyle ST, Kochetkova M. Breast cancer stem cells and the immune system: promotion, evasion and therapy. J Mammary Gland Biol Neoplasia. 2014;19(2):203-211.

44. Jeong YJ, Hk O, Park SH, Bong JG. Association between inflammation and cancer stem cell phenotype in breast cancer. 2018;15(2):2380-2386.

45. Leroith D, Roberts $C T$. The insulin-like growth factor system and cancer. Cancer Lett. 2003;195(2):127-137.

46. Brahmkhatri VP, Prasanna C, Atreya HS. Insulin-like growth factor system in cancer: novel targeted therapies. Biomed Res Int. 2015;2015:538019-24.

47. Goldberg JE, Schwertfeger KL. Proinflammatory cytokines in breast cancer: mechanisms of action and potential targets for therapeutics. Curr Drug Target. 2010;11(9):1133-1146.

48. Soria G, Ofri-Shahak M, Haas I, et al. Inflammatory mediators in breast cancer: coordinated expression of TNF $\alpha$ \& IL- $1 \beta$ with CCL2 \& CCL5 and effects on epithelial-to-mesenchymal transition. BMC Cancer. 2011;11:130.

49. Somja J, Demoulin S, Roncarati P, et al. Dendritic cells in Barrett's esophagus carcinogenesis: an inadequate microenvironment for antitumor immunity? Am J Pathol. 20132013;182036(6):2168-2179.

50. Kumar JD, Kandola S, Tiszlavicz L, Reisz Z, Dockray GJ, Varro A. The role of chemerin and ChemR23 in stimulating the invasion of squamous oesophageal cancer cells. Br J Cancer. 2016;114(10):1152-1159.

51. Xu CH, Yang Y, Wang YC, Yan J, Qian LH. Prognostic significance of serum chemerin levels in patients with non-small cell lung cancer. Oncotarget. 2017;8(14):22483-22489.

52. Bozaoglu K, Curran JE, Stocker CJ, et al. Chemerin, a novel adipokine in the regulation of angiogenesis. J Clin Endocrinol Metab. 2010;95(5):2476-2485. 
53. Lorincz AM, Sukumar S. Molecular links between obesity and breast cancer. Endocr Relat Cancer. 2006;13(2):279-292.

54. Perrier S, Caldefie-Chézet F, Vasson MP. IL-1 family in breast cancer: potential interplay with leptin and other adipocytokines. FEBS Lett. 2009;583(2):259-265.
55. Catalán V, Gómez-Ambrosi J, Rodríguez A, et al. Increased levels of chemerin and its receptor, chemokine-like receptor-1, in obesity are related to inflammation: tumor necrosis factor- $\alpha$ stimulates mRNA levels of chemerin in visceral adipocytes from obese patients. Surg Obes Relat Dis. 2013;9(2):306-314.

\section{Publish your work in this journal}

Breast Cancer - Targets and Therapy is an international, peerreviewed open access journal focusing on breast cancer research, identification of therapeutic targets and the optimal use of preventative and integrated treatment interventions to achieve improved outcomes, enhanced survival and quality of life for the cancer patient.
The manuscript management system is completely online and includes a very quick and fair peer-review system, which is all easy to use. Visit $\mathrm{http}: / / \mathrm{www}$.dovepress.com/testimonials.php to read real quotes from published authors.

Submit your manuscript here: https://www.dovepress.com/breast-cancer---targets-and-therapy-journal 